\title{
Transtorno obsessivo-compulsivo: da psicopatologia como disciplina científica à psicopatologia fenomenológica
}

\section{Obsessive-compulsive disorders: from psychopathology scientific discipline to Phenomenological Psychopathology}

\author{
Ana Maria Lopez Calvo de Feijoo ${ }^{1}$ \\ Carolina Dhein ${ }^{2}$
}

\section{Resumo}

O objetivo deste estudo consistiu em alcançar as divergências e as convergências de duas perspectivas em psicopatologia: psicopatologia como disciplina científica e psicopatologia fenomenológica. Por meio de um estudo teórico, pretendeu-se esclarecer que o modo como cada uma dessas perspectivas compreende a consciência é que sustenta todo o desenvolvimento de suas teses e práticas em psicopatologia. Para dar concretude ao tema desenvolvido, foram investigados os estudos das duas perspectivas sobre o transtorno obsessivo-compulsivo. Enquanto a psicopatologia, como disciplina científica, toma a consciência em sua substancialidade e, consequentemente, atém-se à sintomatologia para realizar o diagnóstico conclusivo, a psicopatologia fenomenológica sustenta a consciência em seu fluxo espaço-temporal e atém-se à vivência do espaço e tempo. Concluímos que ambas, embora se diferenciem no modo como entendem a consciência, têm em comum a desconsideração do horizonte histórico de constituição de sentidos. Com este estudo, acreditamos contribuir para a ampliação das teorias e práticas em psicopatologia.

Palavras-chave: Psicopatologia; Disciplina científica; Fenomenologia; Transtorno obsessivo-compulsivo; Consciência

\begin{abstract}
The aim of this study is to achieve divergences and convergences of two perspectives in psychopathology: psychopathology as scientific discipline and phenomenological psychopathology. Through a literature revision, we intend to clarify that the way each one that perspectives understands the conscious supports all development of its thesis in psychopathology to develop a theme, we take in to considerations the studies of two
\end{abstract}


perspectives about obsessive-compulsive disorders. While psychopathology as scientific discipline understands the conscience as substantially and is based on symptomatology to make conclusive diagnostics; phenomenological psychopathology understands conscience in its space-time flow and is based on space end time experience. We conclude that the psychopathology as scientific discipline and phenomenological psychopathology although that differ in the way they understand the conscience; they have in common the disregard of the historical horizon of structure. We believe that this study to take contributions to development theories and practices of psychopathology.

Keywords: Psychopathology; Science disciplinary, Phenomenology; Obsessive-compulsive disorders; Conscience

\footnotetext{
${ }^{1}$ Universidade do Estado do Rio de janeiro - UERJ - Rio de Janeiro (RJ), Brasil. E-mail: ana.maria.feijoo@gmail.com

${ }^{2}$ Universidade do Estado do Rio de Janeiro - UERJ - Rio de Janeiro (RJ), Brasil. E-mail: carolinadhein@hotmail.com
}

Recebido: 13/3/2017

Aceito: 4/4/2017 


\section{Introdução}

A patologia do psiquismo humano é uma área de estudo que tem como objeto a consciência em suas expressões patológicas. O modo como uma específica perspectiva em psicopatologia abarca e define a consciência vai determinar suas elaborações explicativas ou compreensivas dos fenômenos psicopatológicos.

A psicopatologia, como disciplina científica, tem por base, em seus estudos sobre as enfermidades psíquicas, a noção de consciência como algo dado espacialmente e materialmente. Logo, trata-se de uma interioridade substancializada, determinada pelo biológico ou pelo psíquico. A noção de psicopatologia em um modelo disciplinar vem se enquadrando, cada vez mais, às exigências do modelo científico, em que as enfermidades são abrangidas em um prisma totalmente sintomatológico e biologizante, protagonizado pelo modelo determinista e explicativo causal. As enfermidades, assim apreendidas, têm como modelo explicativo uma lógica determinista, em que cabe buscar as causas dos transtornos psíquicos que se encontram no âmbito do somático, onde a consciência fica reduzida às relações neurais.

Observa-se, no DSM V (2014), um radical afastamento de modelos compreensivos na descrição das enfermidades psíquicas. Diante dessas constatações, algumas questões se impõem: Qual é a importância de se marcar essas duas posições em psicopatologia quais sejam, a psicopatologia como disciplina científica e a psicopatologia fenomenológica? Elas não estariam tratando do mesmo, no entanto, com roupagens diferentes? O modo como cada uma dessas perspectivas entende a consciência para construir suas teorias e práticas é marcante e decisivo, em termos de encaminhamento e de tratamento do transtorno obsessivo-compulsivo? Ambas não estariam desconsiderando a radical cooriginalidade homem-mundo, na medida em que mantêm a ideia de consciência? A redução da compreensão dessas expressões do homem ao biológico e a um consequente quadro sintomatológico não acabaria por obscurecer a dimensão existencial da experiência humana? Cabe esclarecer que o termo existencial, aqui, tem como referência a noção de ek-sistencia de Heidegger, que apontou para o caráter de inseparabilidade homem e mundo e, portanto, compõe uma unidade cooriginária, chamada por este filósofo de ser-no-mundo (Heidegger, 2003).

Para acompanhar o modo como a psicopatologia como disciplina científica e a psicopatologia fenomenológica procederam em seus estudos de psicopatologia, tomou-se 
como mote desta discussão a categoria diagnóstica que, atualmente, recebe a denominação de Transtorno obsessivo-compulsivo (TOC).

Primeiramente, a fim de contextualizar a presente discussão, mostraremos em linhas gerais, como a psicopatologia se edificou como disciplina científica e, mais especificamente, caracterizou o comportamento de extremo controle, pensamentos obstinados e incessante dúvida como patologia. Essas classificações foram sofrendo transformações, em diferentes épocas, até chegarem aos manuais de categorizações, por meio de descrições sintomatológicas das doenças mentais.

Em um segundo momento, retomaremos as bases fenomenológicas que tentam descrever e compreender o fenômeno do comportamento de extremo controle, pensamentos obstinados e incessante dúvida, fenomenologicamente. Nestas bases, a enfermidade psíquica é compreendida como vivência, ou seja, algo que se dá na cooriginalidade corpo e espírito e o que importa é a experiência, daí a denominação - assumida pelos estudiosos da psicopatologia fenomenológica - de vivência anancástica.

Por fim, discutiremos os pontos de divergência e convergência nos dois modos de compreensão dos sofrimentos psíquicos, o disciplinar e o fenomenológico, tomando por base a noção de consciência e demonstrando que ambos diferem no modo como apreendem esta noção. A perspectiva disciplinar entende a consciência de modo empírico, sustentada pelo viés biológico, e a perspectiva fenomenológica compreende a consciência como fluxo espaço-temporal. No entanto, ambas desconsideram o caráter histórico em que a existência em qualquer perspectiva de normal ou patológica - se constitui. Assim, foram expostos argumentos a favor de que outros estudos em psicopatologia sejam realizados, de modo a considerar o caráter histórico das expressões humanas.

\section{A psicopatologia como disciplina científica}

A psicopatologia se caracteriza como uma disciplina autônoma, situada na interlocução da psicologia e da psiquiatria, na medida em que toma como objeto de estudo não apenas desvios quantitativos da normalidade, mas também alterações qualitativas complexas da mente, que requerem um diálogo com a medicina. A psicopatologia guarda diferenças significativas em relação à psiquiatria. A primeira se encarrega de estudar a anormalidade das manifestações psíquicas, na forma de conceitos. Já a psiquiatria, concerne à lida com o enfermo psíquico, ou seja, com o caso clínico concretamente, realizando 
diagnósticos e encaminhando tratamentos, seja na forma medicamentosa, ou psicoterapêutica. Em síntese, o saber psicopatológico é o campo de investigação do sofrimento psíquico que se expressa na interseção da prática da psicologia e da psiquiatria (Nobre de Melo, 1981).

A psicopatologia teve início com os trabalhos do médico alienista francês, discípulo de Philippe Pinel, Jean E. D. Esquirol (1772-1840), considerado o fundador da disciplina (Paim, 1993). Antes dos trabalhos de Pinel e Esquirol, a loucura era atribuída a causas hipotéticas, relacionadas a lesões cerebrais (Pessotti, 2006). A partir da rigorosa observação do comportamento dos pacientes, protagonizada por Esquirol (1838), a psicopatologia procurou classificar as sintomatologias das chamadas doenças mentais em quadros nosológicos cada vez mais específicos, de acordo com suas formas clínicas. São elas: a Idiotia, a Demência, a Mania e as Monomanias.

Posteriormente, concentrando suas pesquisas no mesmo modelo anatomopatológico da medicina em geral, a psicopatologia novamente se encarregou de encontrar as causas das doenças mentais - causas essas atribuídas a lesões orgânicas localizadas no cérebro, com base nos trabalhos dos chamados freniatras. Com esses estudos, a psicopatologia caracterizou-se como uma disciplina científica de base positivista e organicista. No entanto, ocorreu que, com exceção das doenças de origem infecciosa, como a sífilis, não foi possível identificar as lesões cerebrais que se determinassem como causas da maior parte das doenças mentais. $\mathrm{Na}$ ausência dessas comprovações, a psicopatologia voltou a se caracterizar por suas descrições sintomatológicas. Como exemplo, Pessotti (2006) citou os trabalhos de Kraepelin como sendo de natureza basicamente sintomatológica, a partir da qual esse estudioso procurou demarcar as características clínicas das doenças. Ainda que Kraepelin (1921) mantivesse, como foco, os quadros clínicos das doenças, acreditava que os sintomas eram expressões provenientes de distúrbios cerebrais.

A psicopatologia sofreu, ao longo de seu constante desenvolvimento, diversas influências do campo científico, tanto da corrente positivista, como da fenomenológica e da organicista. Aos poucos, porém, em virtude do espaço cada vez mais sedimentado dos avanços tecnológicos expressos pela neurociência, foi se legitimando de forma cada vez mais empírica e pragmática. No entanto, como ainda não foram totalmente comprovadas as relações entre a lesão neurológica e a sintomatologia apresentada pelo paciente, predomina na atuação psiquiátrica o enquadre das doenças mentais pela sintomatologia apresentada.

Uma prova da existência de tantos estudos e divulgação dos manuais que descrevem a Psicopatologia Fenomenológica Contemporânea, 2017;6(1):52-71 
sintomatologia dos diferentes transtornos é a constante ampliação e modificação do Manual de diagnóstico e estatística dos transtornos mentais (DSM). O fato é que o DSM é considerado, atualmente, referência oficial para a consulta e diagnóstico de tais transtornos.

O DSM, em suas primeiras versões, apresentava tanto as descrições fenomenológicas influenciadas pelo trabalho de Karl Jaspers, como também uma forte aproximação com a corrente psicanalítica em seu caráter interpretativo. A marca descritiva e a interpretativa apareciam na designação nominal dos transtornos e em suas fundamentações. Na quarta edição do DSM, houve um claro afastamento, tanto da dimensão compreensiva da fenomenologia, quanto da dimensão interpretativa da psicanálise, ou de qualquer tentativa de fundamentação teórica, passando a predominar a mera descrição sintomatológica e, portanto, universal, das alterações psíquicas, enquadradas em diversas categorias diagnósticas. Na recém-lançada quinta edição, mais categorias diagnósticas foram adicionadas. A transformação sofrida ao longo das décadas de existência do DSM pode ser considerada uma tentativa de acolher, cada vez mais, uma linguagem universal e não comprometida com interpretações teóricas. Um sistema baseado em sintomas permite que todos os psiquiatras de diferentes orientações teóricas possam reconhecer as características das desordens mentais. Entretanto, com a preocupação do DSM em manter uma linguagem ateórica, ocorreu uma redução à catalogação de sintomas e aproximação, cada vez mais marcante, com a fundamentação biológica, em razão dos avanços nas pesquisas científicas. Estas caminham na direção das desregulagens neuronais como causas das desordens mentais e, consequentemente, favorecem o império do tratamento farmacológico (Pessotti, 2006).

Conforme apontado, a tendência a naturalizar a loucura, reduzindo-a ao biológico, mais especificamente a fatores genéticos, remonta de uma fase inicial dos estudos sobre o assunto. Desde então, os sofrimentos psíquicos passaram a receber o estatuto de doença mental, configurando-se como objetos de estudo do campo da psicopatologia. A fim de esclarecer o modo como essa transformação da análise sobre as doenças mentais aconteceu, demonstrou-se, neste trabalho, como os comportamentos e características físicas foram elencados, até o que atualmente se encontra nos manuais de diagnósticos com a denominação de Transtorno obsessivo-compulsivo (TOC).

\section{Transtorno obsessivo-compulsivo: gênese e sintomatologia}

As ideias obsessivas, - caracterizadas como invasivas e acompanhadas de Psicopatologia Fenomenológica Contemporânea, 2017;6(1):52-71 
comportamentos compulsivos, eram descritas, até o século XVIII, como sendo de ordem das possessões demoníacas, marca da forte influência religiosa, característica daquele período histórico (Gentil, Lotufo-Neto \& Bernik, 1997). Com as transformações das forças político-econômicas do ocidente, em torno do século XIX, pouco a pouco a loucura, outrora associada a fenômenos religiosos, ou mesmo artísticos, foi adquirindo estatuto de doença, passando a ser objeto de estudo e tratamentos médicos (Foucault, 1978). Com relação à obsessão, Rudinesco e Plon (1998) afirmaram que o termo foi introduzido, pela primeira vez, por Jules Falret (1824-1902), médico alienista francês, para designar o acometimento de ideias patológicas indesejadas nos indivíduos.

Segundo Black e Grant (2015), o transtorno obsessivo compulsivo, como síndrome diagnóstica, foi descrito, inicialmente, na primeira metade do século XIX, por Esquirol, por meio do conceito de monomanias. Em sua obra fundamental Des maladies mentales, publicada em 1838, Esquirol criou o conceito de monomanias para designar alterações focais do psiquismo na esfera cognitiva ou volitiva. As monomanias, consideradas insanidades parciais, foram divididas em três categorias: intelectuais, afetivas e instintivas. Esquirol (1838) descreveu como esses pacientes ruminavam incessantemente um mesmo tema. Tavares (2000), ao pesquisar sobre os comportamentos impulsivos, relatou que as monomanias instintivas podiam ser consideradas a primeira tentativa de descrição nosológica dos comportamentos do espectro impulsivo-compulsivo, uma vez que eram caracterizadas como uma irresistível tendência para ações patológicas, em que o paciente sente um impulso que a razão e a vontade não são capazes de coibir.

Posteriormente a Esquirol, Kraepelin (1921), em 1915, reuniu síndromes, como cleptomania, oniomania e piromania, sob o nome de impulsos mórbidos, caracterizadas pela impossibilidade do domínio de determinadas ações, nas quais o paciente se vê impulsionado por motivos internos.

Foi em 1905 que Freud (1905/1996) introduziu o elemento psíquico na base de seus estudos sobre as psicopatologias. Em Três ensaios sobre a sexualidade, introduziu, de forma mais consolidada, a noção de neurose obsessiva. Tal noção, segundo ele, indicava a presença de ideias obsessivas, vivenciadas como indesejáveis e acompanhadas de atos compulsivos. A neurose obsessiva estava correlacionada aos mecanismos de defesa e à fixação em fases primitivas do desenvolvimento da sexualidade (Rudinesco \& Plon, 1998). Cabe lembrar que, devido à aproximação da psicopatologia com a psicanálise, o termo neurose obsessiva, 
oriundo da teoria psicanalítica de Freud, foi utilizado por muito tempo nos manuais de psicopatologia, para nomear o quadro hoje conhecido como Transtorno obsessivo compulsivo.

Essa breve exposição sobre como o Transtorno obsessivo-compulsivo se estabeleceu, procurou demonstrar as primeiras tentativas de se formular um enquadramento conciso a respeito desse comportamento. Conforme já mencionado, os manuais de diagnóstico de doenças mentais foram, pouco a pouco, se afastando da preocupação em fundamentar tais doenças e, portanto, se distanciando tanto da terminologia, quanto da fundamentação psicanalítica nas quais estiveram apoiados inicialmente. Atualmente, no DSM V, as descrições dos comportamentos obsessivos e compulsivos aparecem como alterações de algumas categorias diagnósticas distintas. São elas: o próprio Transtorno obsessivo-compulsivo; os transtornos alimentares - especificamente a compulsão alimentar ou bulimia nervosa; os transtornos relacionados ao uso de substâncias; os transtornos de ansiedade; os transtornos depressivos e o transtorno de controle dos impulsos. Este último apresenta-se desdobrado nas seguintes síndromes: transtorno explosivo intermitente, cleptomania, piromania, jogo patológico, tricotilomania e transtorno de controle dos impulsos sem outras especificações, que inclui, por exemplo, a compra compulsiva.

É, no entanto, no próprio Transtorno obsessivo compulsivo que a obsessão e a compulsão aparecem descritas no DSM, como que caracterizando a peculiaridade de tal transtorno. Diferentemente do que ocorre nos demais transtornos citados, em que o ato compulsivo aparece de forma isolada, ou seja, sem obsessão. É importante ressaltar que, na atual e última versão do DSM, o TOC não faz mais parte dos transtornos de ansiedade, como na versão anterior. Segundo Black e Grant (2015), a diferença fundamental para o critério de diagnóstico do TOC, com relação aos comportamentos obsessivos e compulsivos é a conjugação desses dois elementos, de forma a eliminar um sentimento tomado como negativo, tal como o temor por contaminação, por exemplo. Neste caso, o ato de lavar as mãos repetidas vezes ocorre para anular a ideia temerosa de sofrer uma contaminação. $\mathrm{Ou}$ seja, existindo pensamentos obsessivos, os atos compulsivos acontecem como forma de reduzir a ansiedade provocada pela invasão e persistência dessas ideias e tais comportamentos não visam gratificação, mas sim o alívio do sofrimento.

Os critérios de diagnóstico do TOC são, então, apontados no DSM V, em primeiro lugar, pela presença de ambos os comportamentos: obsessões e compulsões, sendo que as 
obsessões são descritas como pensamentos, impulsos ou imagens recorrentes e persistentes, que em algum momento, durante a perturbação, são experimentados como intrusivos e indesejados e que, na maioria dos indivíduos, causam acentuada ansiedade e consequente sofrimento. Já os comportamentos compulsivos, são descritos no DSM V como comportamentos repetitivos (p.ex. lavar as mãos, organizar, verificar), ou atos mentais (p.ex. orar, contar ou repetir palavras em silêncio) que o indivíduo se sente compelido a executar, em resposta a um pensamento obsessivo, ou de acordo com regras que devem ser rigidamente aplicadas. O segundo critério consiste em examinar se os atos repetitivos tomam tempo ou causam sofrimento na vida do indivíduo. $\mathrm{O}$ terceiro critério diz respeito à ausência de efeitos fisiológicos provocados pelo uso de certas substâncias, por exemplo. O quarto e último critério se refere ao fato de que os comportamentos não estejam associados a outros transtornos primários.

No que tange aos encaminhamentos do tratamento psiquiátrico, o TOC, na maioria das vezes, é tratado por meio farmacológico, principalmente antidepressivos e ansiolíticos, com o objetivo de diminuir e administrar a ansiedade do paciente. Com os avanços da neurociência, direcionada às descobertas do funcionamento cerebral, as medicações farmacológicas se apresentam como meio para alterar a desregulagem identificada nas características das desordens cerebrais. Associada à intervenção farmacológica, a terapia cognitivo-comportamental tem se apresentado como via hegemônica de tratamento psicoterapêutico, que, com suas técnicas específicas, procura alterar os pensamentos e comportamentos dos pacientes.

A partir dessa exposição, pudemos acompanhar como a psicopatologia trata, em suas investigações, a caracterização sintomatológica de um dado comportamento, apontando para a sua anormalidade e denominação. Amparada no mesmo modelo de sua disciplina mãe - a medicina - a tarefa da psiquiatria se dirige ao diagnóstico e à prescrição. Sua fundamentação se encontra, de forma hegemônica, apoiada nos modelos organicistas, sinalizando um retorno ao movimento de seu surgimento, há mais de um século, quando a loucura passou a ser associada à noção de doença e fundamentada pelo organicismo.

Em psicopatologia, pode-se proceder a partir de um reducionismo das doenças mentais ao orgânico, ou de uma preponderância do psíquico sobre o somático. Seja com uma ou outra dessas duas estratégias de lida com a psicopatologia e com a prática psiquiátrica, mantém-se a noção de consciência em uma ordem material, que se encontra em uma 
interioridade e contraposta ao mundo, ou seja, ao exterior. Essa visão da doença mental é dicotômica, uma vez que polariza homem e mundo. É mecanicista, já que a doença ocorre por mecanismos internos, pelos quais se dá o funcionamento do indivíduo, e reducionista, na medida em que toda a doença mental fica caracterizada pelo funcionamento do organismo.

Este estudo mostra, também, por meio de uma análise fenomenológica das vivências um modo distinto daquele com que a psicopatologia, em seu caráter disciplinar, vem apresentando a doença mental - a postura da psicopatologia e da psiquiatria que pretende retomar a experiência em sua originalidade, ou seja, antes de qualquer redução ao biológico.

A psiquiatria com bases na fenomenologia de Husserl, tal como desenvolvida por diferentes psiquiatras, dentre eles Ellenberger (1958), Minkowski (1968), Binswanger (1987) e Gebsattel (1969), traçou um caminho diferente do que hoje se estabelece. Esses psiquiatras tiveram uma formação na qual predominava a explicação biologizante para as doenças mentais, mas, na tentativa de sair do modelo médico, viram na fenomenologia uma possibilidade de cogitar as expressões bizarras do homem como existenciais, escapando da redução ao elemento orgânico.

\section{A presença da fenomenologia na psicopatologia e na psiquiatria}

Antes de iniciar a apresentação da apropriação da concepção fenomenológica da consciência intencional pelos psiquiatras fenomenólogos, convém esclarecer sobre os dois grandes métodos que são utilizados, quando se pretende pensar os transtornos psíquicos. São eles: o explicativo e o compreensivo. Segundo Dilthey (2000), o primeiro se constitui em um recurso das ciências naturais; o segundo, das ciências humanas.

No método explicativo, a ênfase pode recair no biológico, buscando-se a etiologia e os mecanismos fisiopatológicos. Se a base for da ordem do psíquico, a averiguação ocorre nas experiências infantis como origem dos traumas atuais, ou, ainda, nos fatores ambientais que condicionam o comportamento do indivíduo. No método compreensivo, recorre-se à fenomenologia, com o propósito de buscar o sentido da vivência do homem transtornado.

A proposta fenomenológica, em psiquiatria, visa romper com o paradigma mecanicista, abarcando o homem em sua totalidade e, rompendo com o dualismo, define o eu como algo da ordem de uma total e radical indeterminação.

A psiquiatria fenomenológica surgiu no início do século XX, como um movimento de insatisfação com o modelo reducionista da psicopatologia tradicional, na qual os sofrimentos 
existenciais eram associados à noção de doença orgânica e seu aporte era basicamente descritivo e sintomatológico. Foi Jaspers (1913/1987), em sua grande obra que versa sobre o tema psicopatologia, que introduziu na psiquiatria o método fenomenológico descritivo, que consiste em captar, empaticamente, e apreender as experiências mórbidas daquele que sofre por diferentes transtornos psíquicos. Ele propôs que, através das definições fenomenológicas e por meio da compreensão subjetiva do médico, se procedesse à descrição das queixas daquele que sofre, mantendo-se fiel à forma como tais descrições se apresentam, como expressão das experiências subjetivas. Por fim, introduziu a importância de uma dimensão compreensiva na tarefa da psiquiatria, em complemento à dimensão explicativa.

A postura descritiva na psiquiatria destaca a relevância em se averiguar a psicopatologia atendo-se às modificações na forma como se dá a comunicação do indivíduo. Afirmou Jaspers (1913/1987) que nos processos psicopatológicos a comunicação do paciente se agrava e se complica, impedindo que o sentido seja claro. Isso acontece no plano afetivo, intelectual e com a própria linguística. Por isso, deve o psiquiatra ficar atento às possibilidades de comunicação com o outro, de modo a poder observar as representações existenciais do paciente.

A partir de então, outros estudiosos do psiquismo assumiriam uma postura fenomenológica ante as expressões humanas, Estas expressões passaram a ser compreendidas tomando a consciência como fluxo temporal e espacial, logo, não mais substancializada nem interiorizada. Passou a importar, na lida do psiquiatra com o paciente, o modo como este vivenciava o espaço e o tempo. Assim foi que Ellenberger (1958), Minkowski (1968), Binswanger (1987), Gebsattel (1969), dentre outros, passaram a compreender o modo bizarro do homem vivenciar o mundo. Ellenberger foi um persistente estudioso do tema, trazendo a publicação dos estudos de psiquiatria fenomenológica. Minkowski estudou e investigou o modo como aqueles que, acometidos por uma tristeza profunda, experienciavam o tempo. Binswanger insistiu que o que caracterizava as manias e as melancolias era a vivência do tempo e do espaço, mas foi Gebsattel (1969) o estudioso que mais se ateve àquilo que denominou de vivência anancástica.

No Brasil, a tentativa de trazer ao público a psicopatologia fenomenológica, diferenciando-a das demais, já foi elaborada por outros estudiosos do tema. Feijoo (1998) apresentou a possibilidade de acompanhar a vivência maníaca, por meio das diferentes etapas da psicopatologia fenomenológica, tal como classificada por Ellenberger (1958). Moreira e 
Bloc (2012) assinalaram essa diferença, mostrando como, no transtorno bipolar, o que estava em jogo era a vivência do tempo. Leite e Moreira (2009) apresentaram uma interpretação da depressão mediante uma perspectiva fenomenológica em Tellenbach e Tatossian. Santos (2013) teceu considerações sobre a angústia e a culpa presentes no transtorno obsessivo-compulsivo. Para tanto, apoiou seus argumentos em Kierkegaard, Heidegger e Merleau-Ponty. Neto e Messas (2016) mostraram a diferença entre um diagnóstico de esquizofrenia pelo modelo operacional e pelo modelo fenomenológico, esclarecendo que tal diferença afeta, também, o tratamento.

\section{A vivência anancástica: método construtivo-genético}

O termo anancástica foi introduzido por Donath, em 1896 (citado por Gebsatell, 1969), referindo-se tanto às fobias, como às obsessões. Anancástica é uma palavra derivada do grego anankástica, em que ananke significa força, obsessão e fatalidade. A vivência anancástica foi objeto de estudo de Gebsattel, que procurou fazer uma investigação antropológica existencial do mundo dos compulsivos, para alcançar o significado da vivência anancástica fracassada.

A vivência anancástica fracassada significa tomar a existência como se esta estivesse arrastada pelo destino, em seu caráter de inevitabilidade e, portanto, pela impossibilidade de fugir de si próprio. Gebsattel (1969) denominou esse transtorno primário de atitude anancástica fracassada e acreditava que essa vivência possuía uma natureza fóbica.

Gebsattel (1969) considerou que, para compreender a enfermidade psíquica, o método descritivo de Jaspers era insuficiente, no que dizia respeito ao conhecimento das estruturas subjetivas do paciente. Por isso, em seus estudos sobre psicopatologia, com base no método construtivo-genético, passou a considerar a concordância ontológica dos sintomas biológicos e anímicos. Assinalou a importância de se investigar, por meio de uma análise estrutural, as conexões e inter-relações entre os dados observados e os estados de consciência, pressupondo uma unidade fundamental no estado de consciência do indivíduo, partindo em busca de um denominador comum, ou seja, da gênese. Gebsattel, assim, passou a investigar a relação entre as perturbações biológicas e psíquicas do doente, na sua clínica psiquiátrica, chegando à conclusão de que o transtorno básico é a experiência do tempo presente em diferentes transtornos psicopatológicos, atendo-se ao estudo dos comportamentos obsessivo-compulsivos. Em seus estudos sobre a psicopatologia da vivência anancástica, 
Gebsattel concluiu que, para alcançar este diagnóstico, era necessária a presença da tríade que compõe a espinha dorsal dessa vivência: obsessão, angústia e compulsão.

A vivência da obsessão se refere a um fenômeno alheio ao eu, em que este se comporta como espectador. A experiência se torna perturbadora e o paciente atua no sentido de suprimi-la, daí caracterizar-se pela luta, pela ruminação. A obsessão possui uma peculiar estrutura dialética que nunca acaba, suspende-se, mas inicia novamente. Trata-se de um transtorno da vontade, que, como tal, nasce no eu, mas este eu não a domina. Não é que o sujeito não queira dominar sua obsessão, senão que ele não pode.

A angústia se mostra como temor angustiado, que se expressa pelo medo de que, uma vez não cumprindo os rituais, algo aconteça. Gebsattel referiu-se à angústia em dois níveis diferentes: angústia secundária e angústia primária.

A angústia secundária é reativa. Primeiramente, o paciente acredita que algo irá acontecer, ao deixar de realizar seus rituais e isso o obriga a realizá-los. A angústia secundária se apresenta pela crença de que algo só acontecerá se os rituais falharem. A angústia se transforma na experiência esmagadora, que inicia com pequenas coisas até formar uma cadeia que aprisiona.

Desse círculo vicioso entre a angústia primária e a secundária resulta a dificuldade de parar, daí a compulsão por não poder finalizar, uma vez que permanece a dúvida e a necessidade de assegurar-se. A incerteza sobre a realização exata do ato leva a pessoa à fragmentação da ação, pois toda a atenção é dirigida aos movimentos, que necessitam ser controlados e comprovados, em sua exatidão. Por isso, são tantas e tantas vezes repetidos. Qualquer desatenção ou deslize destrói o efeito do ato, sendo obrigatório reiniciá-lo. A repetição pode se dar apenas pelo pensamento, na forma de ruminações e de recapitulações. A compulsão se dá através da ação fragmentada, pela necessidade de exatidão. Assim, ocorre uma luta incessante para alcançar a perfeição dos atos, perfeição esta que escapa constantemente. Daí a perturbação, momento em que a perfeição exterior não inclui, simultaneamente, o processo interior de devir, impedindo a sua expansão no tempo, e a autorrealização do próprio eu.

Afirmou Gebsattel (1969) que se trata de um transtorno provocado pela necessidade de segurança, acentuado pela incerteza que paralisa, seguindo-se, então, o fracasso, pela impossibilidade de confiar em si mesmo. Compreende-se, portanto, a grande angústia que acomete o paciente e, ainda segundo Gebsattel, é esta angústia que se transforma em um 
comportamento anancástico. A angústia, portanto, deixa transparecer um transtorno mais básico: na perturbação do sujeito nas suas relações com o mundo, surge o fenômeno fóbico. A angústia que se apresenta na síndrome anancástica se distingue da angústia nas fobias puras.

A dúvida presente no comportamento anancástico se compõe de dois elementos: dúvida e ação. Esta vivência se estrutura a partir de uma dúvida e uma reação contra essa dúvida basal, em caráter permanente. Muitas vezes, essas pessoas se referem aos pensamentos que induzem à dúvida e à consequente necessidade de verificação.

Assim sendo, a vivência anancástica diz respeito ao que, atualmente, os manuais denominam Transtorno obsessivo-compulsivo. A atitude anancástica se fundamenta na tentativa da resolução acirrada daquilo que parece ilógico, mas, ao mesmo tempo, precisa ser verificado. Parece mesmo que a dupla natureza implícita na síndrome obsessivo-compulsiva é uma constatação da presença da dúvida, que se apresenta, ao mesmo tempo em que a luta contra ela se pronuncia. Disse Gebsattel (1969) que aparecem em tensão elementos que se referem à determinação e ao acaso; à temporalidade e à eternização; à liberdade e à repressão.

Gebsattel (1969) aludiu à dupla natureza da atitude anancástica, pela presença de um "psiquismo perturbado", geralmente, pela fobia anancástica, que se expressa por atitudes de repúdio e obsessão, pela angústia do nojo, ou pelo medo de contaminações e, ainda, pela angústia da culpa e dos escrúpulos religiosos. A pessoa reage a essas ideias por meio de seu "psiquismo defensivo", que se dá por atos compulsivos. A vivência anancástica se expressa através de uma insegurança crônica, de uma experiência de tempo sem devir e pela incapacidade de agir.

A insegurança crônica pelo lado pático e cognitivo-volitivo responde ao duplo aspecto da síndrome de coerção ao "psiquismo perturbador" e ao "psiquismo defensivo". O indivíduo sente-se ameaçado por uma deformação que anula sua pessoa. Ele se vê impulsionado a buscar um apoio que se encontraria na pureza absoluta, na limpeza absoluta, na bondade absoluta, na exatidão, na veracidade, na justiça absoluta, que são evocadas contra o poder deformador e desordenador, aparecendo na forma de pedantismo, programação, puritanismo, rigor, fanatismo. Defendeu Gebsattel que, em termos de ação, esse paciente faz o que não pretende fazer e não pode fazer o que pretende. Daí a denominação de transtorno da capacidade de agir - construir. Essa dificuldade aparece quando o paciente quer empreender algo novo, bem como completar o que iniciou, mas não consegue, na medida em 
que há uma ruptura entre a ação e a realização. Ele avança para o futuro - pelo fluxo da vida - porém, não executa objetivamente a ação. Por isso, depois de realizada a ação, a execução é posta em dúvida, surgindo, então, a impossibilidade de confiar em si.

Na vivência anancástica, há um bloqueio do devir e uma tentativa de eternização do

presente. É uma enfermidade da vivência temporal, em que o existente tenta resolver o paradoxo do tempo. Sabe-se temporal, porém, quer-se eterno. Acredita que, pelo seu caráter de controle, pode escolher a sua permanência temporal, mas, ao mesmo tempo, por se perceber no fluxo temporal, tem consciência de sua temporalidade. Daí a tentativa fracassada de fixar o tempo. Novamente, neste paradoxo, reside o malogro.

A prática psiquiátrica em uma base fenomenológica, tal como desenvolvida por Gebsattel, passou a ater-se, no que diz respeito à vivência anancástica, ao modo como a comunicação se apresenta no discurso do paciente, ou seja, minucioso e repetitivo, uma vez que o paciente precisa ter certeza de que todos os detalhes daquilo que ele vivencia estão sendo fielmente repassados. Esta preocupação vem acompanhada de extrema ansiedade, pela necessidade de exatidão. Na linguagem, o indivíduo mostra a confusão que envolve o ato de pensar, que transparece na sua comunicação da experiência. O pensamento obsessivo se evidencia com toda força e a dúvida se apresenta constantemente nas questões trazidas pelo paciente. A pessoa acometida dessa vivência sabe o quanto é ilógica, mas não consegue deixar de pensar. Devido à confusão proveniente da proliferação de ideias e pensamentos ocorre, muitas vezes, a fuga de ideias. Outra situação que frequentemente aparece nos relatos desse paciente é a culpa - culpa esta, muitas vezes, totalmente ilógica, mas que o deixa tenso e apreensivo. Infelizmente, Gebsattel não se referiu a como se dava a sua intervenção clínica nessas situações.

Concluindo os esclarecimentos das duas perspectivas em psicopatologia, ou seja, a disciplinar e a fenomenológica, surgem outras questões: não estariam as duas perspectivas dizendo a mesma coisa? Em que elas diferem?

\section{Transtorno obsessivo-compulsivo e vivência anancástica: divergências e convergências}

Tanto na perspectiva da psicopatologia como disciplina científica com base em um modelo explicativo, quanto na perspectiva fenomenológica em um modelo compreensivo, o que está em questão é o modo como ambas as perspectivas se apropriam da concepção de consciência. Na psicopatologia científica, a consciência é tomada como algo da ordem de 
uma interioridade e substancializada, seja constituída por uma matriz biológica ou psíquica. Na psicopatologia fenomenológica, a consciência é compreendida como transcendência e é apreendida como fluxo temporal, portanto, não substancializada.

Com relação ao denominado Transtorno obsessivo-compulsivo, pode-se pensar que a perspectiva fenomenológica, em psicopatologia, se edifica a partir de um posicionamento crítico à redução das experiências humanas ao aspecto biológico e, consequentemente, ao modelo sintomatológico de compreensão do modo de ser do homem. Isso ocorre justamente pelo fato da fenomenologia tratar das psicopatologias como algo que se dá na vivência temporal e espacial, logo transcendente e não imanente.

Ora, se a consciência é percebida pela fenomenologia como uma síntese de vivências temporais que, como tais, ocorrem na copertença homem-mundo, não há como considerar essas vivências por uma relação de causalidade, não se pode afirmar que algo acontece primeiro, originando outro acontecimento. Este modo de entender a consciência difere totalmente daquele que trabalha com a redução à interioridade - espaço onde se desdobram as relações de causalidade -, colocando-a como posicionadora de mundo. Daí é que surgem os modelos dicotômicos de interpretação das situações do homem, tais como interno/externo; orgânico/psíquico; biológico/social.

$\mathrm{Na}$ compreensão fenomenológica da consciência como fluxo espaço-temporal, é que se dá a cooriginalidade com o mundo e a experiência passa a ser compreendida como uma unidade totalizadora. A chamada vivência anancástica, fenomenologicamente compreendida, passa a ser apreendida a partir da unidade existencial entre psíquico e biológico e, por isso, Gebsattel (1969) afirmou que é a vivência do tempo que contorna a experiência obsessivo-compulsiva, deixando clara a tentativa de fundamentação do sofrimento que não seja meramente descritiva, nem sintomatológica. É no devir existencial que a possibilidade dos sofrimentos existenciais é entendida de modo mais fundamental.

Constata-se, portanto, que a principal contribuição do pensamento fenomenológico aos estudos em psicopatologia é, justamente, o empenho em se compreender a consciência para além de uma visão fragmentada entre homem e mundo.

A partir das breves exemplificações dos trabalhos dos autores citados, observou-se a preocupação em não reduzir os sofrimentos existenciais a categorias aprioristicamente concedidas, bem como em não recorrer a métodos explicativos, visando encontrar uma determinada causalidade mecânica no processo dos ditos adoecimentos psíquicos. 
Constatamos, por outro lado, que os estudiosos da psicopatologia fenomenológica, embora tenham considerado a unicidade homem-mundo, não levaram em conta o horizonte histórico de constituição de sentidos. Ou seja, consideraram o espaço e o tempo como determinações da consciência, mas não como algo que se constitui de acordo com as determinações de um tempo historicamente constituído.

Jaspers (1913/1987) buscou, ainda, uma integração da fenomenologia compreensiva e descritiva com as explicações determinísticas das doenças mentais. Gebsattel (1969), ao conceber os transtornos psíquicos como alterações da dimensão temporal da existência, pareceu desconsiderar, ainda, o caráter histórico-hermenêutico, isto é, as condições historiais nas quais o homem, desde sempre, está lançado. Neste sentido, embora atribuindo os sofrimentos existenciais ao devir temporal próprio da existência humana, assim como às alterações nas formas de estar no mundo, tais pensamentos mostram-se ainda articulados às alterações presentes no próprio indivíduo, sem acenar para as condições de possibilidades históricas. Ambas as concepções se mantêm na perspectiva da subjetividade.

Propõe-se, portanto, que outros estudos em psicopatologia retornem para antes das perspectivas disciplinares e fenomenológicas, para que possam, então, se aproximar daquilo que, por ser marca de nosso tempo, provocam as expressões compulsivas (Heidegger, 1954/2012). Para tanto, é necessário apropriar-se do pensamento filosófico de Heidegger, pois, embora este tenha sido viés de inspiração para muitos dos autores da psicopatologia fenomenológica, eles, aparentemente, têm desconsiderado o existencial ser-no-mundo (Heidegger, 1927/2003).

Faz-se pertinente apontar para estudos que já pretenderam proferir considerações sobre o modo como as psicopatologias se constituem historicamente com base no pensamento tardio de Heidegger. Dentre esses estudos, cita-se Feijoo e Lessa (2015), que mostraram de que modo a fenomenologia e a hermenêutica podem ampliar o leque de possibilidades de interpretação dos fenômenos humanos ditos psicopatológicos.

\section{Considerações finais}

Neste estudo, optou-se pela consciência como elemento de diferenciação de ambas as perspectivas em psicopatologia. A importância de se marcar as duas posições em psicopatologia ocorre pelo fato de que ao se apreciar diferentes modos de desenvolver uma questão, mais se torna possível libertar-se de noções que se estabeleceram como verdades 
naturalmente dadas.

Com relação ao fato de que, tanto a psicopatologia disciplinar, quanto a fenomenológica estariam na mesma dinâmica, apenas com roupagens diferentes, pôde-se concluir que o modo como cada uma dessas perspectivas compreende a consciência para construir suas teorias e práticas é marcante e decisivo, em termos de encaminhamento e de tratamento das psicopatologias. Na primeira perspectiva, há redução da compreensão dessas expressões do homem ao biológico e a um consequente quadro sintomatológico, cujo tratamento acontece em termos de medicação e correção do comportamento. Na segunda perspectiva, a preocupação centra-se em não deixar que se obscureça a dimensão existencial da experiência humana.

Neste segundo entendimento, ou seja, fenomenológico, considera-se que a redução da compreensão dessas expressões do homem ao biológico e, consequentemente a um quadro sintomatológico, acaba por obscurecer a dimensão existencial da experiência humana, deixando que o paciente se esqueça do seu caráter de liberdade. A conquista da dimensão existencial e a consequente liberdade do homem é a proposta de uma clínica psicológica com bases fenomenológicas. 


\section{Referências}

Binswanger, L. (1987). Mélancolie et manie: études phénoménologiques. Paris: Presses Universitaires de France. (Original publicado em 1960).

Black, D. W. \& Grant, J. E. (2015). Guia para o DSM-5: complemento essencial para o manual diagnóstico e estatístico dos transtornos mentais. (J. S. Antoniazzi, E. Tesche, G. R. Borges, M. L. Oliveira, Scientific Linguagem LTDA, Trad.) Porto Alegre: Artmed.

Dilthey, W. (2000). Dos escritos sobre hermenéutica: el surgimiento de la hermenéutica y los esbozos para una crítica de la razón histórica. (Antônio Gómez Ramos, Trad.). Madrid: Ediciones Istmo S.A. (Original publicado em 1900).

DSM V. (2014). Manual Diagnóstico e Estatístico dos Transtornos Mentais. Porto Alegre: Artmed.

Ellenberger, H. (1958) Introducción clínica a la fenomenología psiquiátrica y al análisis existencial. In R. May, E. Angel, \& H. Ellenberger. (1977). Existencia: nueva dimensión en Psiquiatría y Psicología (pp. 123-162). (Sánchez Pacheco, Trad.). Madrid: Gredos. (Original publicado em 1958).

Esquirol, J. E. (1838). Des maladies mentales considérées pour les rapports médicals, hygiéniques et médico-legal (Vol 1). Paris: J.B. Baillière.

Feijoo, A. M. (1998). A vivência maníaca numa proposta fenomenológico-existencial. Informação Psiquiátrica, 17 (2), 57-62.

Feijoo, A. M., \& Lessa, M. B. (2015). Psicopatologia: fenomenologia, literatura e hermenêutica. Rio de janeiro: IFEN.

Foucault, M. (1978). História da Loucura. (José Teixeira Coelho Neto, Trad.). São Paulo: Perspectiva. (Original publicado em 1972).

Freud, S. (1996). Três ensaios sobre sexualidade. Edição standard brasileira das obras psicológicas completas de Sigmund Freud (Vol. 7). (Paulo Dias Correa, trad.) Rio de Janeiro: Imago. (Original publicado em 1905).

Gebsattel, V. (1969). Imago hominis. (Beatriz Romero, Trad.). Madrid: Gredos.

Gentil, V., Lotufo-Neto, F. \& Bernik, M. A. (orgs). (1997). Pânico, Fobias e Obsessões. São Paulo: Edusp.

Heidegger, M. (2012). A questão da técnica. In Ensaios e conferências (pp. 11-38). (Carneiro Leão; Márcia Schuback, Gilvan Fogel, Trad.). Petrópolis: Vozes e Bragança Paulista: Editora Universitária. (Original publicado em 1954). 
Heidegger, M. (2003). Ser y tiempo. (Rivera Cruchaga, Trad.). Madrid: Gredos. (Original publicado em 1927).

Husserl, E. (2007). Investigações lógicas (Vols. 1-2). (P. Alves \& C. Marujão, trad.). Lisboa: Centro de Filosofia da Universidade de Lisboa. (Original publicado em 1901).

Jaspers, K. (1987). Psicopatologia geral: psicologia compreensiva, explicativa e fenomenologia. São Paulo: Atheneu. (Samuel Pena Reis, Trad.). RJ/SP: Atheneu. (Original publicado em 1913).

Kraepelin, E. (1921). Manic-depressive insanity and paranoia. (R. M. Barclay, Trad.). Edinburgh: E\&S Livingstone.

Leite, M. E., \& Moreira, V. (2009). A contribuição de Tellenbach e Tatosssian para a compreensão fenomenológica da depressão. Arquivos Brasileiros de Psicologia, 61 (3), 46-56.

Minkowiski, E. (1968). Le temps vécu. Paris: Delachaux Et Niestlé. (Original publicado em 1933).

Moreira, V., \& Bloc, L. (2012). Fenomenologia do tempo vivido no transtorno bipolar. Psicologia: Teoria e Pesquisa, 28 (4), 443-450.

Neto, H. G., \& Messas, G. (2016). O diagnóstico psiquiátrico pelo modelo operacional e pela psicopatologia fenomenológica: um paralelo entre os modelos, através de um estudo de caso. Psicopatologia Fenomenológica Contemporânea, 5 (1), 22-24.

Nobre de Melo, A. L. (1981). Psiquiatria. Rio de Janeiro: Guanabara Koogan.

Paim, I. (1993). História da psicopatologia. São Paulo: EPU.

Pessotti, I. (2006). Sobre a Teoria da Loucura no século XX. Temas em Psicologia, 4 (2), 113-126.

Rudinesco, E., \& Plon, M. (1998) Dicionário de Psicanálise. Rio de Janeiro: Zahar

Santos, G. (2013). A angústia e a culpa no transtorno obsessivo-compulsivo: uma compreensão fenomenológico-existencial. Revista da Abordagem Gestáltica, 19 (1), $85-91$.

Tavares, H. (2000). Jogo patológico e suas relações com o espectro impulsivo-compulsivo. Tese de doutorado. Faculdade de Medicina da Universidade de São Paulo, São Paulo. 